\title{
Purification and characterization of a tryptic peptide of Borrelia burgdorferi flagellin, which reduces cross-reactivity in immunoblots and ELISA
}

\author{
Christiane Rasiah, ${ }^{1}$ Emile Schiltz, ${ }^{2}$ Jan Reichert $^{1}$ and ARnold Vogt $^{1 *}$ \\ ${ }^{1}$ Institut für medizinische Mikrobiologie und Hygiene, Hermann-Herder Strasse 11, 7800 Freiburg, FRG \\ ${ }^{2}$ Institut für organische Chemie und Biochemie, Albertstrasse 21, 7800 Freiburg, FRG
}

(Received 7 May 1991; revised 19 July 1991; accepted 16 September 1991)

\begin{abstract}
In man the early immune response in Lyme disease is primarily directed against the endoflagellin antigen. Isolated flagellar protein of Borrelia burgdorferi suggests itself as a suitable test antigen. However, cross-reactivity between flagellins of B. burgdorferi, Escherichia coli, Bacillus subtilis, Proteus mirabilis and Salmonella typhimurium was demonstrated by immunoblotting and ELISA with polyclonal rabbit-hyperimmune-sera. Tryptic cleavage of recombinant $B$. burgdorferi $41 \mathrm{kDa}$ flagellin, expressed in $E$. coli, produced a peptide fragment which was recognized exclusively by antisera to Borrelia species. This peptide was designated as the $14 \mathrm{kDa}$ fragment due to its migratory behaviour in SDS-PAGE. The fragment is part of the variable region of the flagellin, as proven by amino acid sequencing. The flagellin peptide was employed as an antigen in ELISA and immunoblot assays, testing the polyclonal sera mentioned above. The specificity was superior to that obtained with the intact recombinant flagellin.
\end{abstract}

\section{Introduction}

Lyme borreliosis is a chronic infectious disease caused by the tick-borne spirochaete Borrelia burgdorferi (Steere et al., 1983). This multisystemic disorder starts typically with an erythematous skin lesion, erythema chronicum migrans (ECM), which in some patients progresses to acrodermatitis chronicum atrophicans (ACA). Other manifestations include neurological, cardiac and articular syndromes (Steere 1989). Isolation of B. burgdorferi is, due to the fastidious nature of this organism, difficult and time consuming. Diagnosis of Lyme disease therefore relies on serological assays. The early immune response of most patients is directed primarily against the $B$. burgdorferi flagellin, a $41 \mathrm{kDa}$ polypeptide, which constitutes the flagella. Isolated flagellar protein suggests itself as a suitable test antigen. Hansen et al. $(1988,1991)$ were able to improve serodiagnosis by using either purified $B$. burgdorferi flagella in a direct ELISA or biotinylated flagella in a $\mu$-capture ELISA. There are, however, pronounced amino acid sequence similarities between the flagellin of $B$. burgdorferi and those of other spirochaetes (Borrelia hermsii, 95\%, Treponema pallidum, $60 \%$ ), and other unrelated eubacteria (Salmonella typhimurium, $51 \%$; Escherichia coli, $51 \%$; Serratia marcescens, $50 \%$; Bacillus subtilis, $49 \%$ ) (Gassmann et al., 1991). The
B. burgdorferi flagellin consists of 336 amino acids; conserved and semi-conserved regions are located exclusively at the $\mathrm{N}$ - and $\mathrm{C}$-termini of the protein, whereas the central region (amino acids 131-266) exhibits variability. Epitopes cross-reacting with hyperimmune sera raised against the flagella of $B a$. subtilis and Treponema phagedenis have recently been identified. These epitopes are located in the highly conserved regions at the $\mathrm{N}$ - and $\mathrm{C}$-termini of the flagellin. Many Borrelia-specific epitopes were found in the variable central region (Gassmann et al., 1991) and this part, therefore, should represent a suitable antigen. Here we report on the characterization and purification of a tryptic peptide of recombinant flagellin, expressed in $E$. coli. This peptide is part of the variable region of the flagellin and exhibits only Borrelia-specific epitopes within the limits of tested bacterial genera.

\section{Methods}

Bacteria and culture conditions. Borrelia hermsii, Borrelia parkeri, Borrelia turicatae (provided by Dr. Baranton, Institut Pasteur, Paris, France) and Borrelia burgdorferi GeHo (isolated from a skin biopsy by Dr. Pelz, Institut für Medizinische Mikrobiologie und Hygiene, Freiburg, FRG) were grown in modified Kelly's medium (Barbour et $a l ., 1983)$ to the late exponential phase. Microbes were harvested by centrifugation $(5000 \mathrm{~g}, 30 \mathrm{~min}$ at room temperature) and washed twice 
with PBS containing protease inhibitors ( $5 \mathrm{mM}$-EDTA, 5 mM-sodium tetrathionate, $5 \mathrm{~mm}$-benzamidine, $0.5 \mathrm{~mm}$-PMSF). Final bacterial pellets were resuspended in the same buffer and disintegrated by ultrasonication.

Expression and purification of recombinant $B$. burgdorferi flagellin. Escherichia coli $\mathrm{HB101}$, containing $\mathrm{pBb} 20$ as a cloning vector (Gassmann et al., 1991), was cultivated in a heart-brain bouillon containing ampicillin $\left(100 \mu \mathrm{g} \mathrm{ml}^{-1}\right)$ for $24 \mathrm{~h}$ at $37^{\circ} \mathrm{C}$. The B. burgdorferi $41 \mathrm{kDa}$ flagellin was expressed as a non-fusion protein.

The cells of a 51 culture were harvested as follows: bacteria were pelleted by centrifugation at $10000 \mathrm{~g}$ for $30 \mathrm{~min}$ and washed twice with cold PBS: the resulting pellet (about $2 \mathrm{~g} \mathrm{l}^{-1}$ ) was resuspended in $20 \mathrm{mM}$ imidazole $/ \mathrm{HCl}$, pH 6.5, containing $8 \mathrm{M}$-urea (Gibco) (starting buffer for the following anion exchange chromatography, final vol. = tenfold vol. of bacterial pellet) and stirred for $2 \mathrm{~h}$ at room temperature. After centrifugation at $27000 \mathrm{~g}$ for $45 \mathrm{~min}$ the urea-extracted recombinant flagellin was found in the supernatant $\left(5-7 \mathrm{mg} \mathrm{ml}^{-1}\right)$. As a first purification step, anion exchange chromatography (DEAECellulose, Serva) was applied (column size; $4 \mathrm{~cm}$ (height) $\times 4.5 \mathrm{~cm}$ (diam.); starting buffer, $20 \mathrm{~mm}$-imidazole/ $\mathrm{HCl}, \mathrm{pH} \mathrm{6.5}$, plus $8 \mathrm{M}$-urea; final buffer, starting buffer plus $1 \mathrm{M}-\mathrm{Na}$ citrate; linear gradient from 0 $100 \%$ of the final buffer; gradient volume, $100 \mathrm{ml}$; flow rate, $48 \mathrm{ml} \mathrm{h}^{-1}$ ]. Fractions (fractions size, $8 \mathrm{ml}$ ) containing recombinant flagellin were pooled and dialysed against distilled water. Precipitated flagellin was resuspended in starting buffer for cation exchange chromatography [SP-Sephadex C-50, Pharmacia; column size; $4 \mathrm{~cm}$ (height) $\times 4.5 \mathrm{~cm}$ (diam.); starting buffer, $50 \mathrm{~mm}-\mathrm{MES}, \mathrm{pH} 6.5$, plus $8 \mathrm{M}$-urea; final buffer, starting buffer plus $1 \mathrm{M}-\mathrm{NaCl}$; linear gradient from $0-100 \%$ of the final buffer; gradient volume, $100 \mathrm{ml}$; flow rate, $48 \mathrm{ml} \mathrm{h}^{-1}$ ). Flagellin-containing fractions (fraction size, $8 \mathrm{ml}$ ) were pooled and dialysed against distilled water. Precipitated, purified recombinant flagellin was stored at $-20^{\circ} \mathrm{C}$. We obtained $12-16 \mathrm{mg}$ protein from a 51 culture. Protein content was determined by a BCAprotein assay (Pierce). After each chromatographic step, fractions were analysed by SDS-PAGE $(12.5 \% \mathrm{gel})$ according to the method of Laemmli (1970).

Tryptic cleavage of recombinant flagellin. Purified recombinant flagellin was resuspended in $0.1 \mathrm{M}-\mathrm{Tris} / \mathrm{HCl}, \mathrm{pH} 7 \cdot 5$, and digested with trypsin (sequencing grade, Boehringer Mannheim) at a ratio of $1 \mu \mathrm{g}$ trypsin per $100 \mu \mathrm{g}$ protein $\left(2-3 \mathrm{mg} \mathrm{ml}^{-1}\right)$ for $4 \mathrm{~h}$ at $37^{\circ} \mathrm{C}$.

Purification of the $14 \mathrm{kDa}$ fragment. For use as an antigen in ELISA and for amino acid analysis, the $14 \mathrm{kDa}$ fragment was purified by gel filtration [Superdex $75 \mathrm{HR}$ 10/30, Pharmacia; buffer, 0.1 M-Tris/HCl (pH 7.5); flow rate, $0.5 \mathrm{ml} \mathrm{min}^{-1}$ ]. The column was calibrated according to the manufacturer's instructions. From a 51 culture we obtained 3-6 $\mathrm{mg}$ of the $14 \mathrm{kDa}$ fragment.

$S D S-P A G E$. Cleavage products were analysed in a Tricine-SDSPAGE system previously described by Schăgger \& von Jagow (1987). Proteins were separated in a $16.5 \% \mathrm{~T}, 3 \% \mathrm{C}$ separating gel $(7 \mathrm{~cm}$ in length) overlaid by a $10 \%$ T spacer gel and a $4 \%$ stacking gel (both $2 \mathrm{~cm}$ in length). Electrophoresis was performed for $16 \mathrm{~h}$ at $15 \mathrm{~mA}$. For molecular mass determination, a prestained low-molecular-mass marker (BRL) was used. After electrophoresis gels were fixed in $50 \%$ (v/v) methanol $/ 10 \%(v / v)$ acetic acid and then stained with $0.025 \%$ (w/v) Coomassie G-250 (Sigma) in 10\% (v/v) acetic acid. Destaining was done in $10 \%(\mathrm{v} / \mathrm{v})$ acetic acid.

Immunoblotting. For immunodetection and $\mathrm{N}$-terminal sequencing, proteins were transferred after electrophoresis to a polyvinylidenfluoride membrane (PVDF, Millipore) as described by Towbin et al. (1979).

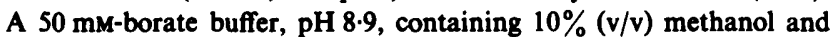
$0.02 \%(v / v) 2$-mercaptoethanol was used as transfer buffer (transfer time, $4 \mathrm{~h}$ ). After transfer, non-specific binding sites of the membrane were blocked with $10 \%(w / v)$ skimmed milk in PBS. Rabbithyperimmune-sera were diluted $1: 1000$ in $10 \%(w / v)$ skimmed milk in
Table 1. Polyclonal rabbit-hyperimmune-sera

\begin{tabular}{|c|c|c|}
\hline Polyclonal sera to: & $\begin{array}{l}\text { Rabbits immunized } \\
\text { with: }\end{array}$ & Rabbit number \\
\hline B. burgdorferi & Intact cells & K248 \\
\hline B. burgdorferi & Whole-cell lysate & K312 \\
\hline B. burgdorferi & $41 \mathrm{kDa}$ flagellin & K 17 \\
\hline B. burgdorferi & $41 \mathrm{kDa}$ flagellin & K314 \\
\hline B. burgdorferi & Recombinant flagellin & K297 \\
\hline B. burgdorferi & Recombinant flagellin & K549 \\
\hline B. burgdorferi & $14 \mathrm{kDa}$ fragment & K265 \\
\hline B. burgdorferi & $14 \mathrm{kDa}$ fragment & K270 \\
\hline B. parkeri & Whole-cell lysate & $\mathbf{K} 1$ \\
\hline B. turicatae & Whole-cell lysate & K4 \\
\hline B. hermsii & Whole-cell lysate & K567 \\
\hline Ba. subtilis & Flagella & K306 \\
\hline E. coli & Flagella & $\mathrm{K} 215$ \\
\hline Proteus mirabilis & Flagella & K110 \\
\hline S. typhimurium & Flagella $\mathrm{H} 1.2$. & K301 \\
\hline S. typhimurium & Flagella $\mathrm{Hi}$ & K267 \\
\hline$T$. phagedenis & Whole-cell lysate & K779 \\
\hline
\end{tabular}

PBS and incubated for $2 \mathrm{~h}$ at room temperature. Immunodetection was done with a peroxidase-conjugated goat-anti-rabbit IgG (Dianova, diluted 1:3000 in 10\%(w/v) skimmed milk in PBS and incubated for $2 \mathrm{~h}$ at room temperature) with diaminobenzidine (Sigma) as substrate. All washing steps were performed with $0 \cdot 1 \%$ (v/v) Tween 20/PBS.

ELISA. ELISA was done in the usual way. Briefly, 96-well flatbottomed microdilution plates (Greiner) were coated for $24 \mathrm{~h}$ with the previously determined optimal antigen concentration of $(a)$ intact recombinant flagellin $(0.025 \mu \mathrm{g}$ per well) and $(b)$ purified $14 \mathrm{kDa}$ fragment $(0.05 \mu \mathrm{g}$ per well) diluted in coating buffer $(0.05 \mathrm{M}$-carbonate buffer, pH 9.5). Coating with intact recombinant flagellin was performed starting from an $8 \mathrm{M}$-urea solution that was diluted in coating buffer to the appropriate concentration (final urea concentration was about $8 \mathrm{mM})$. After washing [0.1\% (v/v) Tween 20/PBS] rabbit-hyperimmune-sera, diluted from $1: 1600$ to $1: 204000$ [dilution buffer; $2 \%(\mathrm{v} / \mathrm{v})$ foetal calf serum, $2 \%(\mathrm{v} / \mathrm{v})$ Tween 20 in PBS], were incubated for $2 \mathrm{~h}$ at room temperature. Detection of antibodies was achieved with peroxidase-conjugated goat-anti-rabbit IgG (Dianova) at a dilution of $1: 3000$, incubated for $2 \mathrm{~h}$ at room temperature. After a third washing step, substrate solution $\left[0.4 \mathrm{mg}\right.$ phenylenediamine $\mathrm{ml}^{-1}$ (Sigma) in citrate buffer, $2 \mu \mathrm{l} 30 \%(\mathrm{v} / \mathrm{v}) \mathrm{H}_{2} \mathrm{O}_{2}$ added prior to use] was added and the mixture was left for $15 \mathrm{~min}$ in a dark chamber. The reaction was stopped with $2 \mathrm{M}-\mathrm{H}_{2} \mathrm{SO}_{4}$ and the optical density was read at $462 \mathrm{~nm}$ (Titertek Multiscan). A commercially available ELISA-test kit, employing intact flagella (Dakopatts), was used according to the manufacturer's instructions.

The cut-off was fixed at an $\mathrm{OD}_{462}$ value of 0.2 for all three assays by comparison of non-immune rabbit sera, which showed mean $\mathrm{OD}_{462}$ values of 0.060 (recombinant flagellin), 0.080 (14 kDa fragment) and $0 \cdot 100$ (ELISA-test kit) in the first dilution step.

Characterization of the $14 \mathrm{kDa}$ fragment. For $\mathrm{N}$-terminal sequencing of the $14 \mathrm{kDa}$ fragment, the tryptic digest was transferred to a PVDFmembrane as described for immunoblotting. After transfer, proteins were stained with 0.1\% (w/v) Coomassie R-250 (Sigma) in 50\% (v/v) methanol. The $14 \mathrm{kDa}$ band was excised and analysed by Edman degradation in a gas-phase sequencer (477A Protein Sequencer with on-line 120 A PTH-Analyzer, Applied Biosystems). To determine the C-terminal sequence, the purified fragment was cleaved with endoproteinase Asp-N (Boehringer Mannheim) at a ratio of $1 \mu \mathrm{g}$ protease per $65 \mu \mathrm{g}$ protein overnight at $37^{\circ} \mathrm{C}$ (digestion of the $14 \mathrm{kDa}$ fragment with carboxypeptidase $A$ and $B$ was not successful). Cleavage products were 
separated by reversed-phase chromatography (HPLC column Pep-S $\mathrm{C} 2 / \mathrm{C} 18$, Pharmacia) and analysed by $\mathrm{N}$-terminal sequencing. Amino acid analysis after acid hydrolysis (Hill, 1965) of the purified $14 \mathrm{kDa}$ fragment was done on a Biotronik amino acid analyser BT $6000 \mathrm{E}$. Additionally, some tryptic peptides of recombinant flagellin that had been purified by reversed-phase chromatography were $\mathrm{N}$-terminally sequenced to provide further information about the $\mathrm{C}$-terminal end of the fragment.

Polyclonal rabbit-hyperimmune-sera. Rabbits were immunized at 4 week-intervals by repeated subcutaneous injections of $50 \mu \mathrm{g}$ purified recombinant $B$. burgdorferi flagellin (sera K297, K549) or $80 \mu \mathrm{g}$ purified $14 \mathrm{kDa}$ fragment (sera K265, K270) in Freund's Complete Adjuvant (FCA). Serum K312 was raised against whole-cell lysates of $B$. burgdorferi GeHo and serum K248 was obtained by intravenous injections of whole organisms (B. burgdorferi $\mathrm{GeHo}$ ) without FCA (Gassmann et al., 1991). Sera K17 and K314 are monospecific sera raised against flagellin of $B$. burgdorferi. Rabbits were immunized as described above with $41 \mathrm{kDa}$ bands excised from preparative SDSpolyacrylamide gels containing about $50 \mu \mathrm{g}$ protein. Hyperimmunesera against whole cell lysattes of $B$. hermsii (serum K 567), B. parkeri (serum $\mathrm{K} 1$ ) and $B$. turicatae (serum K4) were obtained by immunizing the rabbits at 4-week-intervals by repeated subcutaneous injection of $100 \mu \mathrm{g}$ protein in FCA. The hyperimmune-sera against purified flagella from $B$. subtilis (serum K306), E. coli (serum K215), Proteus mirabilis (serum K110), Salmonella typhimurium H1.2. and Hi (sera K301 and K267) were kindly provided by Torsten Schmidt (Freiburg). We thank Alexandra Otto (Freiburg) for kindly providing us with the hyperimmune-sera against whole-cell lysates of Treponema phagedenis (sera K38 and $\mathrm{K}$ 779). $\mathrm{A}$ list of the antisera is given in Table 1.

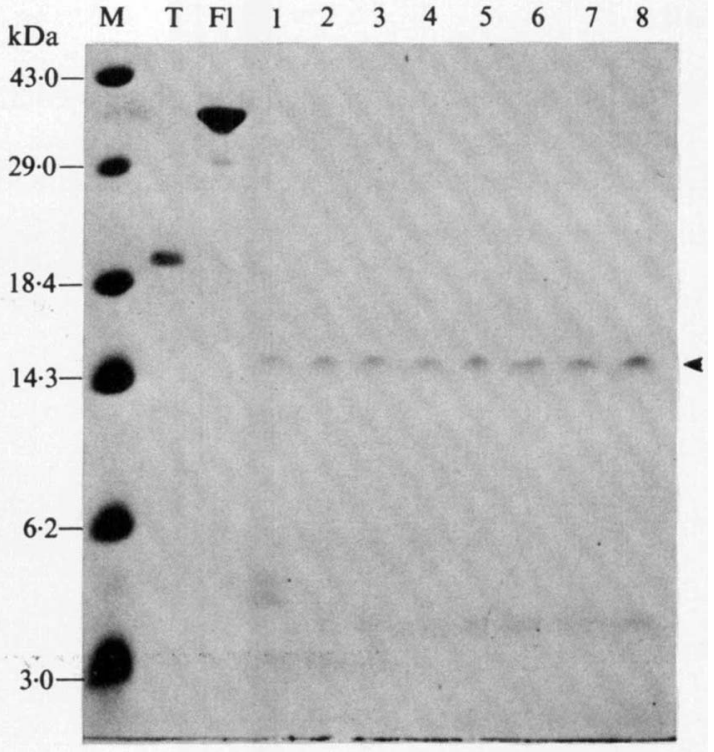

Fig. 1. SDS-polyacrylamide gel $(16.5 \%)$, stained with Coomassie G-250 showing kinetics of cleavage of recombinant $B$. burgdorferi $41 \mathrm{kDa}$ flagellin with trypsin. Lanes: $M$, molecular mass markers; $T$, trypsin; Fl, flagellin (41 kDa); 1-8, aliquots taken at 30 min intervals from $30 \mathrm{~min}(1)$ to $4 \mathrm{~h} \mathrm{(8)}$. The $14 \mathrm{kDa}$ fragment is indicated by the arrowhead.

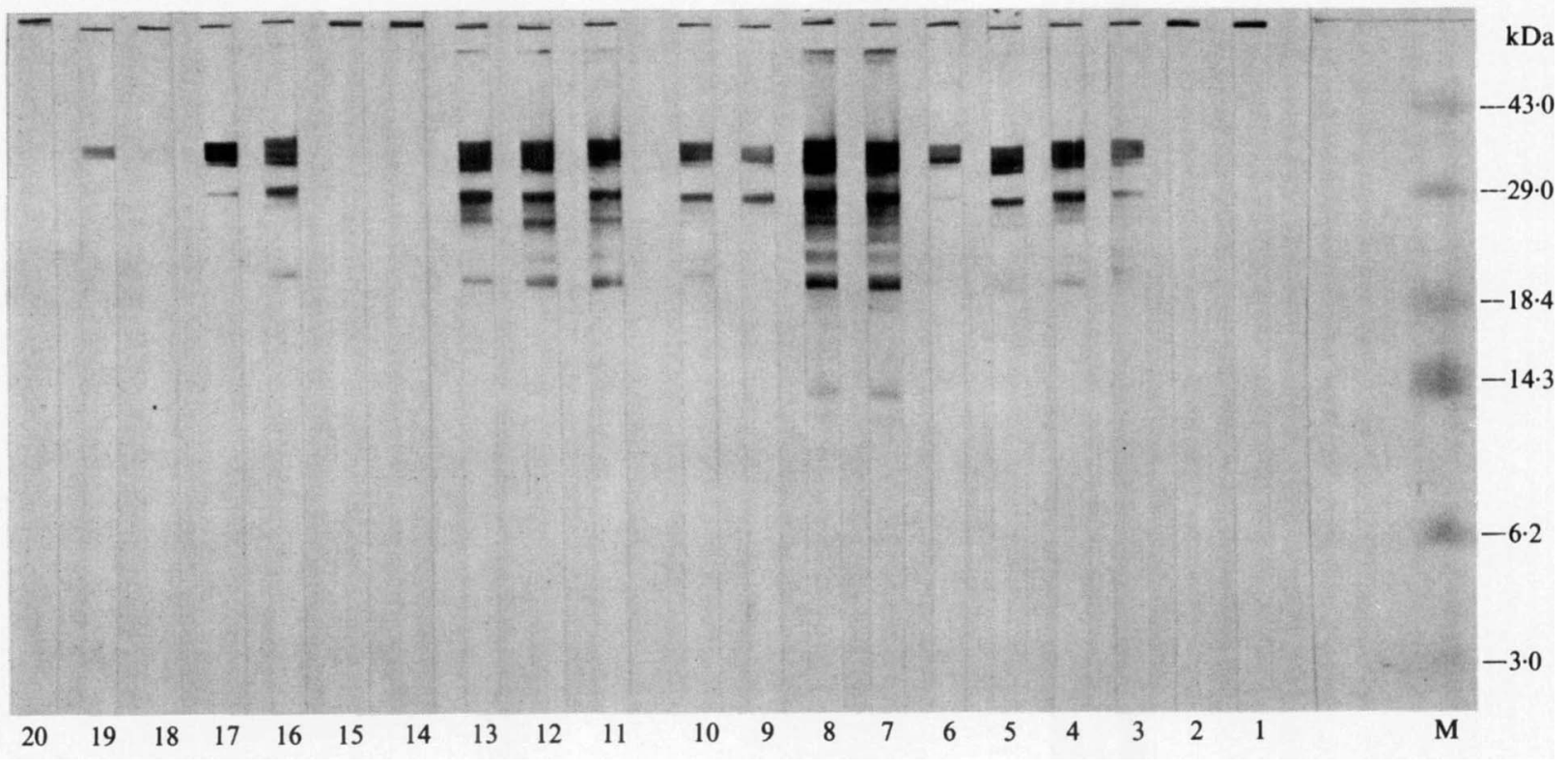

Fig. 2. Immunoblot of IgG-antibodies against recombinant $B$. burgdorferi $41 \mathrm{kDa}$ flagellin of various polyclonal rabbit-hyperimmunesera. Lanes: M, molecular mass markers; 1 , control for the second antibody (peroxidase-conjugated goat-anti-rabbit IgG); 2 , nonimmune rabbit serum; 3, K248 (anti-intact cells of B. burgdorferi GeHo); 4, K312 (anti-whole-cell lysate of B. burgdorferi GeHo); 5 , $\mathrm{K} 17 ; 6, \mathrm{~K} 314$ (anti-41 kDa flagellin of B. burgdorferi); 7, K297; 8, K549 (anti-recombinant flagellin of B. burgdorferi); 9, K265; 10 , K270 (anti-14 kDa fragment); 11, K1 (anti-whole-cell lysate of B. turicatae); 12, K4 (anti-whole-cell lysate of B. parkeri); 13, K567 (antiwhole-cell lysate of $B$. hermsii); 14, K38; 15, K779 (anti-whole-cell lysate of T. phagedenis); 16, K306 (anti-flagella of Ba. subtilis); 17 , K215 (anti-flagella of $E$. coli); 18, K110 (anti-flagella of $P$. mirabilis); 19, K301 (anti-flagella of $S$. typhimurium H1 .2.); $20, \mathrm{~K} 267$ (antiflagella of $S$. typhimurium $\mathrm{Hi}$ ). 


\section{Results}

Purification of recombinant flagellin by combined anion and cation exchange chromatography resulted in a $41 \mathrm{kDa}$ fraction revealing only weak contaminants in the lower molecular mass range $(<30 \mathrm{kDa})$ when analysed in $16.5 \%$ SDS-PAGE (Fig. 1). Almost all higher molecular mass contaminants that could be seen in the crude urea extract, as well as DNA and RNA, were removed by these purification steps. Complete tryptic

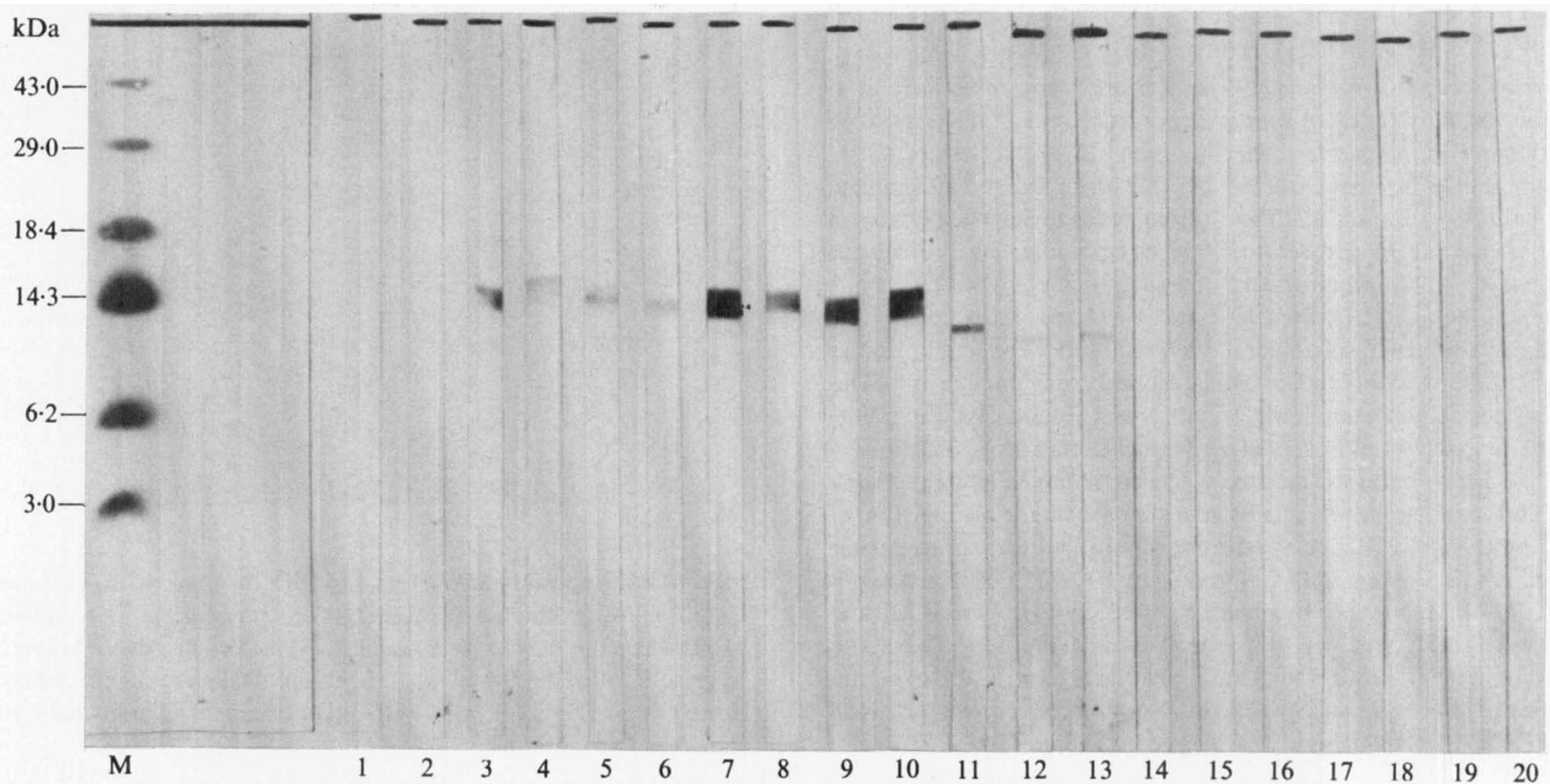

(a)

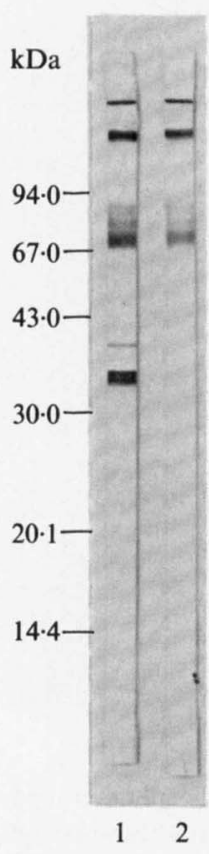

(b)

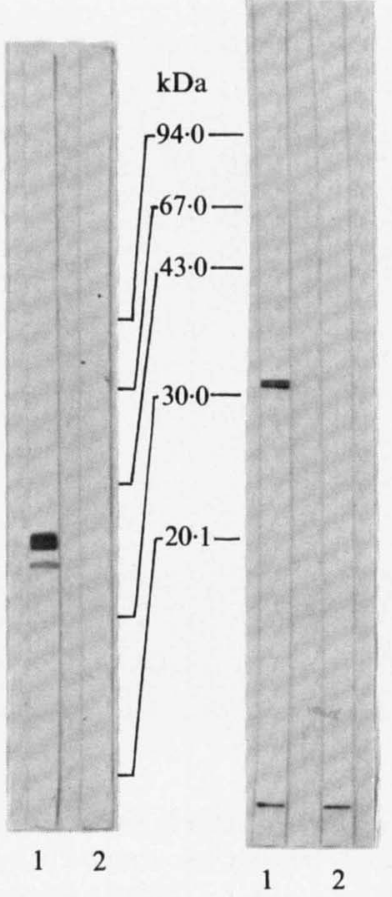

(d)

(e)

(f)

Fig. 4. Immunoblot of IgG-antibodies of rabbit-hyperimmune-sera against (a) whole-cell lysate of $T$. phagedenis (kindly provided by A. Otto, Freiburg, FRG), purified flagella of $(b) E$. coli and (c) Ba. subtilis (kindly provided by T. Schmidt, Freiburg, FRG), and whole-cell lysate of $(d) B$. hermsii $(e)$ B. parkeri and $(f)$ B. turicatae. Lanes: 1, K297 (anti-recombinant flagellin of B. burgdorferi); 2, K270 (anti$14 \mathrm{kDa}$ fragment). 
Table 2. Cross-reactivity of various polyclonal rabbit-hyperimmune-sera with intact flagella, recombinant $41 \mathrm{kDa}$ flagellin and $14 \mathrm{kDa}$ fragment as antigens in immunoblot and ELISA

The assays were carried out as described in Methods; the cut-off point being fixed at an $\mathrm{OD}_{462}$ value of 0.2. The degree of cross-reactivity in the immunoblot assays is indicated: $(-)$, no cross-reactivity; $(+)(+++)$, weak-strong cross-reactivity.

\begin{tabular}{|c|c|c|c|c|c|}
\hline \multirow[b]{2}{*}{ Polyclonal sera to: } & \multicolumn{2}{|c|}{$\begin{array}{l}\text { Immunoblot } \\
\text { B. burgdorferi }\end{array}$} & \multicolumn{3}{|c|}{$\begin{array}{l}\text { ELISA } \\
\text { B. burgdorferi }\end{array}$} \\
\hline & $\begin{array}{l}\text { Recombinant } \\
\text { flagellin }\end{array}$ & $\begin{array}{c}14 \mathrm{kDa} \\
\text { fragment }\end{array}$ & Flagella & $\begin{array}{l}\text { Recombinant } \\
\text { flagellin }\end{array}$ & $\begin{array}{c}14 \mathrm{kDa} \\
\text { fragment }\end{array}$ \\
\hline B. burgdorferi* & +++ & +++ & $1: 204800$ & $1: 204800$ & $1: 51200$ \\
\hline B. hermsii * & +++ & + & 1: 51200 & $1: 51200$ & $1: 12800$ \\
\hline B. parkeri* & $+t+$ & + & $>1: 204800$ & $1: 204800$ & $1: 25600$ \\
\hline B. turicatae & +++ & ++ & $>1: 204800$ & $>1: 204800$ & $1: 25600$ \\
\hline B. phagedenis* & - & - & 1: 1600 & 1: 1600 & $<1: 1600$ \\
\hline$B a$. subtilist & +++ & - & $1: 51200$ & $1: 51200$ & $<1: 1600$ \\
\hline E. coli $\dagger$ & $++t$ & - & $1: 51200$ & $1: 51200$ & $<1: 1600$ \\
\hline P. mirabilis $†$ & + & - & $1: 1600$ & $1: 1600$ & $<1: 1600$ \\
\hline S. typhimurium $\mathrm{H} 1.2 . \dagger$ & ++ & - & $1: 6400$ & $1: 1600$ & $<1: 1600$ \\
\hline S. typhimurium $\mathrm{Hi} \dagger$ & - & - & $1: \quad 1600$ & $<1: \quad 1600$ & $<1: 1600$ \\
\hline
\end{tabular}

- Sera raised against whole-cell lysate.

† Sera raised against flagella.

\begin{tabular}{|c|c|c|c|c|c|}
\hline & 10 & 20 & 30 & 40 & 50 \\
\hline & 1 & 1 & 1 & 1 & \\
\hline 1 & MIINHNTSAI & NASRNNGINA & ANLSKTQEKL & SSGYRINRAS & DDAAGMGVSG \\
\hline 51 & KINAQIRGLS & QASRNTSKAI & NFIQTTEGNL & NEVEKVLVRM & KELAVQSGNG \\
\hline 101 & TYSDADRGSI & QIEIEQLTDE & INRIADQAQY & NQMHMLSNKS & ASQNVRTAEE \\
\hline 151 & LGMQPAKINT & PASLSGSQAS & WTLRVHVGAN & ODEAIAVNIY & AANVANLFSG \\
\hline 201 & EGAQTAQAAP & VQEGVQQEGA & QQPAPATAPS & QGGVNSPVNV & THTVDANTSL \\
\hline 251 & AKIENAIRMI & SDQRANLGAF & QNRLESIKDS & TEYAIENLKA & SYAQIKDATM \\
\hline 1 & TDEVVAATTN & [LTQSAM & IAQAI & CSLLR & \\
\hline
\end{tabular}

Fig. 5. Amino acid sequence of the B. burgdorferi GeHo flagellin (Gassmann et al., 1991). Bold letters, $14 \mathrm{kDa}$ fragment (amino acids 175-252); underlined, Asp- $\mathrm{N}$ peptides of the $14 \mathrm{kDa}$ fragment, identified by $\mathrm{N}$-terminal sequencing; variable part, amino acids $131-$ 266.

cleavage of purified recombinant flagellin produced two peptides with apparent molecular masses of 14 and $4 \mathrm{kDa}$ in SDS-PAGE (Fig. 1).

Figs. 2 and 3 show the results of immunoblotting using recombinant $B$. burgdorferi flagellin and the tryptic digest as antigens. Strong cross-reactions with intact $\boldsymbol{B}$. burgdorferi flagellin were observed using sera raised against the flagella of $B$. subtilis (serum K306), E. coli (serum K215), S. typhimurium H1.2. (serum K301) and sera raised against whole-cell lysates of $B$. hermsii, $B$. parkeri and $B$. turicatae (sera K567, K4, K1). With sera raised against the flagella of $P$. mirabilis (serum K110) and $S$. typhimurium $\mathrm{Hi}$ (serum K267) as well as with sera raised against whole-cell lysate of $T$. phagedenis (serum K 779) only weak cross-reactivity could be seen. The results are summarized in Table 2 . In contrast, serum K297, specific for recombinant B. burgdorferi flagellin, contained antibodies that recognized the 33 and $37 \mathrm{kDa}$ flagellins of $T$. phagedenis and the flagellins of $E$. coli and B. subtilis (Fig. 4). Using the tryptic digest as antigen, only antisera raised against Borrelia species recognized the $14 \mathrm{kDa}$ fragment (Table 2); the $4 \mathrm{kDa}$ peptide seen in Coomassie-stained SDS-polyacrylamide gels was not recognized. No cross-reaction with the flagellins of $T$. phagedenis, $B$. subtilis and $E$. coli was observed using serum K270, specific for the $14 \mathrm{kDa}$ fragment. Antibodies in this serum reacted with the flagellins of B. hermsii, B. parkeri and B. turicatae (Fig. 4).

The results of ELISA using intact recombinant flagellin and purified $14 \mathrm{kDa}$ fragment as antigens corroborate data obtained by immunoblotting (Table 2). The cross-reactions predominantly seen between recom- 

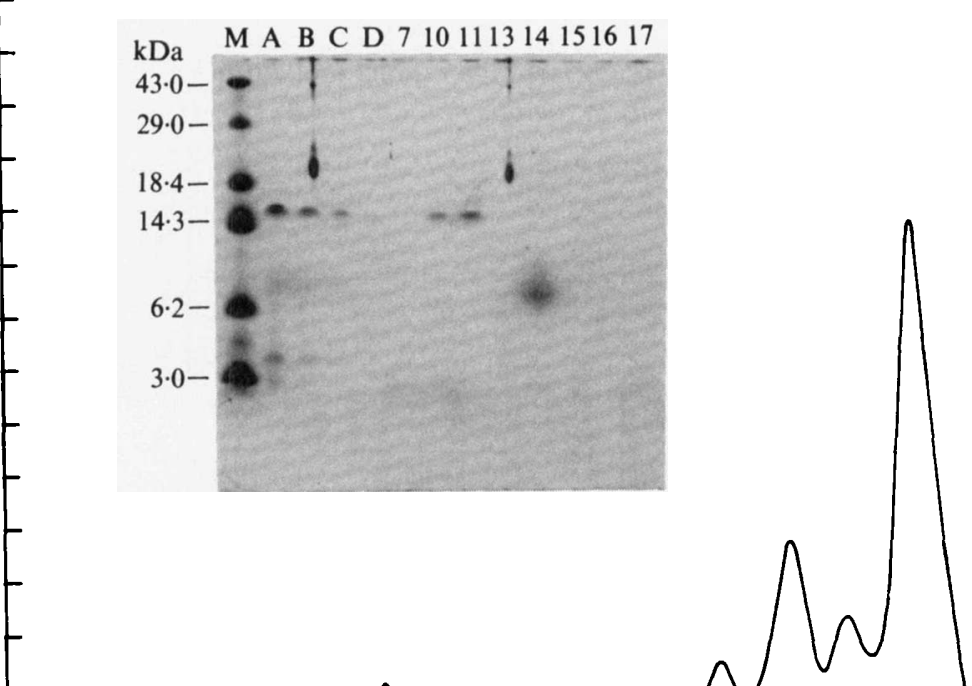

Fig. 6. Purification of the $14 \mathrm{kDa}$ fragment by gel filtration (Superdex 75 HR 10/30). Fractions were lyophilized and separated on a $16.5 \%$ SDSpolyacrylamide gel, stained with Coomassie G-250. Lanes: M, molecular mass markers; A-D, various concentrations of the tryptic digest; 7-17, fractions. Fractions 10 and 11 contain the $14 \mathrm{kDa}$ fragment.

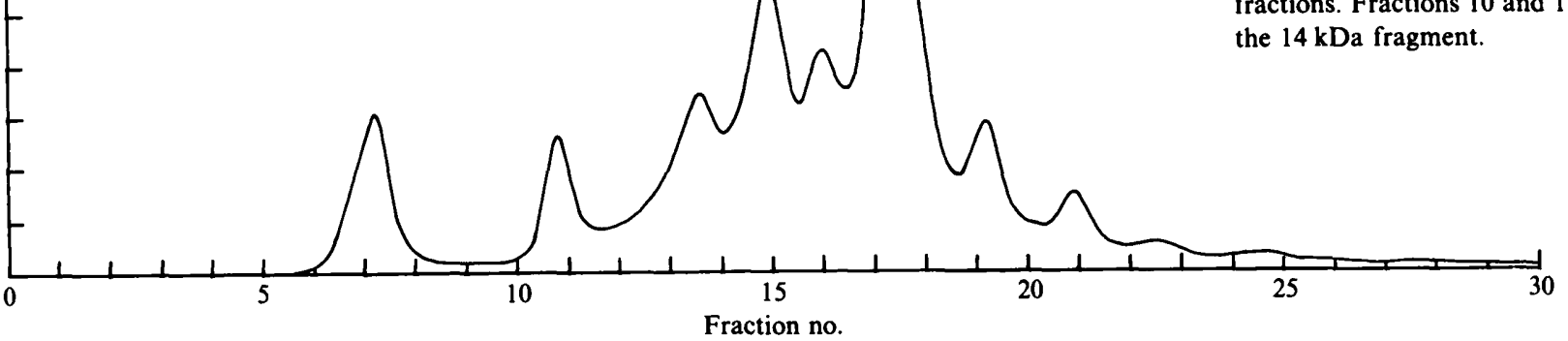

binant flagellin and sera raised against the flagella of $\boldsymbol{B}$. subtilis (serum K306) and E. coli (serum K215) were eliminated when using the $14 \mathrm{kDa}$ fragment as antigen. Using intact $B$. burgdorferi flagella (Flagellum ELISAtest kit, Dakopatts) as antigen, marked cross-reactions were observed with sera raised against the flagella of $B$. subtilis, E. coli (sera K 306 and $\mathrm{K} 215$ ) and with sera raised against whole-cell lysates of $B$. hermsii, $B$. parkeri and $B$. turicatae (sera K567, K4, K1).

Further analysis of the $14 \mathrm{kDa}$ fragment by $\mathrm{N}$ terminal sequencing revealed that the peptide is part of the variable region (amino acids 131-266) of the flagellin (Fig. 5). The first amino acid is valine at position 175. Amino acid analysis of the purified $14 \mathrm{kDa}$ fragment pointed to a possible end at amino acid position 252 . To verify this, the peptide was digested with endoproteinase Asp-N. N-terminal sequence analysis of Asp- $\mathrm{N}$ peptides (purified by reversed phase chromatography) corroborated the result of amino acid analysis. By reversed phase chromatography of tryptic peptides of recombinant flagellin and subsequent $\mathrm{N}$-terminal sequence analysis of some peptides, we were able to identify the hexapeptide that immediately follows the $14 \mathrm{kDa}$ fragment (amino acids 253-258). The $14 \mathrm{kDa}$ fragment (apparent molecular mass in a $16.5 \%$ SDS-polyacrylamide gel) consists of 78 amino acids (amino acids 175-252) which corresponds to a theoretical molecular mass of $8.58 \mathrm{kDa}$. The peptide is rather hydrophobic, particularly in the region of amino acids 182-200, according to Kyte \& Doolittle (1982). Gel filtration revealed that the peptide eluted in a peak that is in accordance with a molecular mass of $28 \mathrm{kDa}$ (Fig. 6, fractions 10 and 11 ).

\section{Discussion}

\section{Preparation and characterization of the 14 kDa fragment}

Tryptic digestion of purified $B$. burgdorferi $41 \mathrm{kDa}$ flagellin, expressed in $E$. coli, resulted in a peptide with an apparent molecular mass of $14 \mathrm{kDa}$. Further characterization by $\mathrm{N}$-terminal sequencing and amino acid analysis revealed that the peptide constitutes a rather hydrophobic part of the variable region of the flagellin. The theoretical molecular mass of the amino acid chain is $8.58 \mathrm{kDa}$ in contrast to the apparent molecular mass of $14 \mathrm{kDa}$ in a $16.5 \%$ SDS-polyacrylamide gel. Slow migration of hydrophobic proteins in SDS-PAGE is not unusual. The result may also depend on the gel system chosen. Schägger \& von Jagow (1987) observed such differences when separating protein in SDS-polyacrylamide gels which differed in their degree of crosslinking. Purification of the $14 \mathrm{kDa}$ fragment by gel filtration revealed that the peptide eluted from the column in a fraction that corresponds to a molecular mass of $28 \mathrm{kDa}$; the molecules may be aggregating due to their hydrophobicity. The $14 \mathrm{kDa}$ fragment is soluble in aqueous buffers, in contrast to recombinant flagellin that is soluble only in high concentrations of urea $(6-8 \mathrm{M})$ or in detergents.

Cross-reaction of recombinant flagellin role of conserved regions and variable parts

The $B$. burgdorferi flagellin that consists of 336 amino acids shows semi-conserved and conserved regions at the 
$\mathrm{N}$ - and C-terminal ends, while the middle part of the protein represents a variable region. B. burgdorferispecific epitopes recognized by rabbit-hyperimmunesera are clustered within a region flanked by amino acids 180-260. Cross-reactive epitopes recognized by sera raised against the flagella of $B$. subtilis and $T$. phagedenis are located in conserved regions of the $\mathrm{N}$ - and $\mathrm{C}$-termini. The amino acid sequence of the $B$. burgdorferi flagellin reveals remarkable similarities to that of $B$. hermsii $(95 \%), T$. pallidum B2 (60\%), S. typhimurium $(51 \%), E$. coli $(51 \%)$, Serr. marcescens (50\%) and Ba. subtilis (49\%) (Gassmann et al., 1991).

Marked cross-reactions were observed in immunoblotting and ELISA between recombinant flagellin and antisera raised against the flagella of $B$. subtilis and $E$. coli as well as with antisera raised against whole-cell lysates of $B$. hermsii, B. parkeri and B. turicatae, the etiological agents of North American tick-borne relapsing fever. The latter are of minor importance in Europe (Barbour \& Hayes, 1986). Only weak cross-reactions were seen using sera raised against the flagella of $P$. mirabilis, $S$. typhimurium H1.2. and sera raised against whole-cell lysates of $T$. phagedenis. This latter result is unexpected because overall sequence similarity of the $B$. burgdorferi flagellin and the $T$. pallidum B2 flagellin is high at $60 \%$; furthermore, class B flagellar proteins of $T$. pallidum and $T$. phagedenis share $67-95 \%$ homology of their N-termini (Norris et al., 1988). Possibly our sera, raised against whole-cell lysates of $T$. phagedenis, contained only less cross-reactive antibodies. The result may be different using sera raised against the flagella of $T$. pallidum or $T$. phagedenis. Conversely a serum specific for $B$. burgdorferi recombinant flagellin revealed a strong cross-reaction with the flagellins of $T$. phagedenis in immunoblotting (Fig. 4).

Among the hyperimmune-sera available, only antisera to the genus Borrelia were reactive using the $14 \mathrm{kDa}$ fragment as an antigen in ELISA and immunoblotting. A serum raised against the $14 \mathrm{kDa}$ fragment showed no cross-reaction with the flagellins of $T$. phagedenis, $B a$. subtilis and $E$. coli in immunoblotting (Fig. 4). Epitopes in the semi-conserved and conserved regions are responsible for the observed cross-reactions. These regions are possibly involved in flagellin export and organelle assembly, whereas variable parts seem to be less important for the structure of the flagella and may therefore represent variable antigenic determinants (Fedorov \& Efimov, 1990; Kuwajima, 1988; Namba et al., 1989). Due to the conserved regions, cross-reactions in routine serology may be traced back to contact with a multitude of motile bacteria.

Hansen et al. (1988) using intact B. burgdorferi flagella as an antigen in ELISA could improve the specificity of Borrelia serology; while Coleman \& Benach (1987) found flagellin eluted from SDS-polyacrylamide gels not to be superior to the whole-cell sonicate as the antigen in ELISA. Wilske et al. (1986) and Zöller et al. (1991) frequently observed antibodies, in immunoblots, against the $41 \mathrm{kDa}$ flagellin in sera of patients without clinical symptoms of borreliosis. These data are in line with the idea that, using flagellin monomers, epitopes in the conserved regions are accessible for antibodies while in the intact flagella most parts of the conserved regions seem to be masked and the epitopes of the central region are exposed. However, even in intact flagella some crossreactive epitopes may be recognized by antibodies as our results using intact flagella as antigen in ELISA show (Table 2). The antisera raised against flagella of $B a$. subtilis and $E$. coli revealed a marked reaction. The crossreactions we observed with intact flagella and recombinant $B$. burgdorferi flagellin mentioned above could be avoided by offering the $14 \mathrm{kDa}$ fragment as an antigen in immunoblotting and ELISA.

Recently, Collins et al. (1991) reported that antibodies in patient sera were exclusively directed against epitopes at the $\mathrm{N}$-terminus by using truncated recombinant fusion proteins of the $B$. burgdorferi flagellin as antigens in immunoblotting; a fragment containing the variable part was not recognized. Gassmann (1991) also obtained disappointing results using a Trp-E fusion protein representing the entire variable part of the $B$. burgdorferi flagellin. Only $35 \%$ of the patient sera tested showed a positive reaction in immunoblotting. These findings cannot be explained by the lack of antibodies specific for epitopes of the variable part of the flagellin, as our data with the $14 \mathrm{kDa}$ fragment convincingly show with rabbit sera. Sera of rabbits immunized with antigen containing Borrelia flagellin, as well as sera of patients with Lyme borreliosis, recognize epitopes in the central region of the flagellin. When technical problems can be excluded (for example too little antigen offered) changes in conformation or post-translational modifications of the fusion proteins expressed in $E$. coli have to be considered. The conformation of a protein plays an important role in the interaction of antibodies and epitopes, as shown by the reaction of patient sera in a PIN-ELISA, using synthetic linear octapeptides as antigens. Only two of twelve Lyme borreliosis patients had antibodies that recognized linear epitopes (Gassmann, 1991).

The tryptic $14 \mathrm{kDa}$ fragment seems to be a suitable antigen for determining specific antibodies in Lyme borreliosis, especially in the early course of the disease. It is not burdened by false positive results and it represents a part of the $B$. burgdorferi flagellin which carries a multitude of Borrelia-specific epitopes (Gassmann et al., 1991). It is soluble in water, easy to handle and may be a convenient antigen for the detection of class-specific antibodies. 
This study has been supported by the Bundesministerium für Forschung und Technik (01KI189098). We gratefully acknowledge the receipt of antisera and antigen preparations from G. Gassmann (K248, K312), A. Otto (K 38, K 779; whole-cell lysate of Treponema phagedenis), T. Schmidt (K110, K215, K267, K301, K 306; flagella of Escherichia coli and Bacillus subtilis) and the excellent technical assistance of S. Burger. We are indepted to Drs S. Batsford and G. Gassmann for critical reading of the manuscript.

\section{References}

Barbour, A. G. \& Hayes, S. F. (1986). Biology of Borrelia species. Microbiological Reviews 50, 381-400.

Barbour, A. G., Burgdorfer, W., Hayes, S. F., Peter, O. \& AESCHLIMANN, A. (1983). Isolation of a cultivable spirochete from Ixodes ricinus ticks in Switzerland. Current Microbiology 8, 123-126.

Coleman, J. L. \& BenACH, J. L. (1987). Isolation of antigenic components from the Lyme disease spirochete: their role in early diagnosis. Journal of Infectious Diseases 155, 756-765.

Collins, C. \& Peltz, G. (1991). Immunoreactive epitopes on an expressed recombinant flagellar protein of Borrelia burgdorferi. Infection and Immunity 59, 514-520.

Fedorov, O. V. \& EFimov, A. V. (1990). Flagellin as an object for supramolecular engineering. Protein Engineering 3, 411-413.

GassmanN, G. S. (1991). Analyse des Flagellingens von Borrelia burgdorferi und antigenetische Charakterisierung des Genprodukts. $\mathrm{PhD}$ thesis, Universität Tübingen, Tübingen, FRG.

Gassmann, G. S., Jacobs, E., Deutzmann, R. \& Göbel, U. E. (1991). Analysis of the fla gene of Borrelia burgdorferi $\mathrm{GeHo}$ and antigenic characterization of its gene product. Journal of Bacteriology 173, 1452-1459.

Hansen, K., Hindersson, P. \& Pederson, N. S. (1988). Measurement of antibodies to the Borrelia burgdorferi flagellum improves serodiagnosis in Lyme disease. Journal of Clinical Microbiology 26, 338-346.

Hansen, K., PII, K. \& LebeCH, A. (1991). Improved immunoglobulin $\mathrm{M}$ serodiagnosis in Lyme borreliosis by using a $\mu$-capture enzymelinked immunosorbent assay with biotinylated Borrelia burgdorferi flagella. Journal of Clinical Microbiology 29, 166-173.
HiLl, R. L. (1965). Hydrolysis of proteins. Advances in Protein Chemistry 20, 37-107.

KYTE, J. \& DoolitTle, R. F. (1982). A simple method for displaying the hydropathic character of a protein. Journal of Molecular Biology 157, 105-132.

KuWAima, G. (1988). Construction of a minimum-size functional flagellin of Escherichia coli. Journal of Bacteriology 170, 3305-3309.

LAEMMLI, U. K. (1970). Cleavage of structural proteins during the assembly of the head of bacteriophage T4. Nature, London 227, 680685.

NAMBa, K., Yamashita, J. \& Vonderviszt, F. (1989). Structure of the core and central channel of bacterial flagella. Nature, London 342, 648-654.

Norris, S. J., Charon, N. W., Cook, R. C., Fuentes, M. D. \& LIMBERGER, R. J. (1988). Antigenic relatedness and N-terminal sequence homology define two classes of periplasmatic flagellar proteins of Treponema pallidum subsp. pallidum and Treponema phagedenis. Journal of Bacteriology 170, 4072-4082.

SCHÄGGER, H. \& VON JAGOW, G. (1987). Tricine-sodium dodecyl sulfate-polyacrylamide gel electrophoresis for the separation of proteins in the range from 1 to $100 \mathrm{kDa}$. Analytical Biochemistry 166, 368-379.

Steere, A. C., Grodzicki, R. L., Kornblott, A. N., Craft, J. E., Barbour, A. G., Burgdorfer, W., Schmid, G. P., Johnson, E. \& Malavista, S. E. (1983). The spirochetal etiology of Lyme disease. New England Journal of Medicine 308, 733-740.

STEERE, A. C. (1989). Lyme disease. New England Journal of Medicine 321, 586-596.

Towbin, H., Staehelin, T. \& GoRdon, J. (1979). Electrophoretic transfer of proteins from polyacrylamide gels to nitrocellulose sheets: procedure and some applications. Proceedings of the National Academy of Sciences of the United States of America 76, 4350-4354.

Wilske, B., Preac-Mursic, V., SChierz, G. \& Von BUSCH, K. (1986). Immunochemical and immunological analysis of european Borrelia burgdorferi strains. Zentralblatt für Bakteriologie, Mikrobiologie und Hygiene A 263, 92-102.

ZölLER, L., BURKHARD, S. \& SCHÄFER, H. (1991). Validity of western immunoblot band patterns in the serodiagnosis of Lyme borreliosis. Journal of Clinical Microbiology 29, 174-182. 